\title{
Effect of uncoated calcium carbonate and stearic acid coated calcium carbonate on mechanical, thermal and structural properties of poly(butylene terephthalate) (PBT)/calcium carbonate composites
}

\author{
G S DESHMUKH*, S U PATHAK, D R PESHWE and J D EKHE ${ }^{\dagger}$ \\ Department of Metallurgical and Materials Engineering, ${ }^{\dagger}$ Applied Chemistry Department, \\ Visvesvaraya National Institute of Technology, Nagpur 440 010, India
}

MS received 13 January 2009; revised 22 August 2009

\begin{abstract}
PBT} / \mathrm{CaCO}_{3}$ composites were prepared in a single screw extruder with particle content varying from $0-30 \%$ by weight. The influence of surface treatment of the particles, with and without stearic acid (SA), on the mechanical, thermal and structural properties was studied. The experiments included tensile tests, impact tests, differential scanning calorimetry (DSC), scanning electron microscopy (SEM), X-ray diffraction (XRD) and Fourier transform infrared spectroscopy. The composite systems containing $\mathrm{SA}$ coated $\mathrm{CaCO}_{3}$ were found to exhibit better mechanical properties as compared to composite systems containing uncoated $\mathrm{CaCO}_{3}$, with the $\mathrm{S} 3$ system $\left(20 \%\right.$ of $\mathrm{SA}$ coated $\left.\mathrm{CaCO}_{3}\right)$ exhibiting best combination of mechanical properties. Thermal study revealed that particle type and content had no influence on the melting temperature but the crystallization temperature, \% crystallinity and thermal stability increased on increasing the $\mathrm{CaCO}_{3}$ content in PBT matrix. Morphological observation indicated that in PBT composites containing SA coated $\mathrm{CaCO}_{3}$, the coupling agent favours a better polymer filler interaction rendering inorganic polymer interface compatible, which is also evident from better mechanical and thermal properties.
\end{abstract}

Keywords. Polymer-matrix composites; mechanical; thermal analysis.

\section{Introduction}

During the last few decades polymer composites have attracted much attention from both industry and academia because of their superior mechanical and thermal properties, light weight, and favourable cost/performance ratio, and hence appear to be suitable replacements for metals and alloys in many industrial applications in fields such as automotive, structural plastics, electronics, packaging, and so on.

Among the various fillers, calcium carbonate $\left(\mathrm{CaCO}_{3}\right)$ is used as important reinforcing filler in thermoplastic industry and has been studied by many researchers who have reported large improvements in mechanical properties such as strength, modulus and toughness. Also it has been reported that the coating of $\mathrm{CaCO}_{3}$ surface with low molecular weight organic compounds like stearic acid changes the interfacial interactions between particles and matrix polymer which modifies the debonding mechanism, failure behaviour and thus, the overall performance of composites. Although there is extensive literature on the

*Author for correspondence (gauri_c2006@yahoo.co.in) use of $\mathrm{CaCO}_{3}$ in polyolefins, such as polyethylene and polypropylene, but studies dealing with use of $\mathrm{CaCO}_{3}$, as filler in polyesters are not much reported.

Poly(butylene terephthalate) (PBT) is an important semicrystalline engineering thermoplastic with many valuable properties including a high rate of crystallization, good solvent resistance, thermal stability, and excellent processing properties. However, pure PBT has low impact strength and heat distortion temperature, which obstruct its application. Much work has been done on PBT blending but few data are reported in the scientific literature on polyester-based composites. As a reinforced method, many researchers have worked extensively on PBT/glass fibre composites. Other fillers used as reinforcements in PBT include oxidized single wall carbon nanotubes, montmorillonite and $\mathrm{SiO}_{2}$.

The present work deals with calcium carbonate $\left(\mathrm{CaCO}_{3}\right) /$ [poly(butylene terephthalate) (PBT)] composites involving two types of filler particles: one was plain $\mathrm{CaCO}_{3}$, the other was stearic acid (SA) coated $\mathrm{CaCO}_{3}$. The study presents a detailed analysis of the effect of filler on the mechanical, thermal and structural properties of PBT based composites, and in particular, to determine the efficiency of the stearic acid coating in improving dispersion 
of $\mathrm{CaCO}_{3}$ into the polyester matrix and promoting interfacial adhesion between the phases.

\section{Experimental}

\subsection{Materials}

The PBT used in this work was supplied by BASF Ultradur, grade ultradur B 2550 having density and melt flow index as $1.30 \mathrm{~g} / \mathrm{cm}^{3}$ and $18 \mathrm{~g} / 10 \mathrm{~min}$, respectively. Calcium carbonate particles, plain and coated with stearic acid, were kindly supplied by 20 MICRONS Limited having particle size, $D(50) 3.47$ microns.

\subsection{Composite preparation}

Two sets of PBT composites (sets $\mathrm{C}$ and $\mathrm{S}$ ) containing two different types of $\mathrm{CaCO}_{3}$ were prepared by melt blending method in a single screw extruder and the filler loadings of both types of $\mathrm{CaCO}_{3}$ were varied as $5 \%, 10 \%$, $20 \%$ and $30 \%$ by weight. Prior to compounding, all the materials were dried at $110^{\circ} \mathrm{C}$ in an oven for atleast $6 \mathrm{~h}$ before use, to minimize the effects of moisture. The temperature of the four heating zones was set to 220, 230, 240, and $250^{\circ} \mathrm{C}$, and the screw speed was fixed at $30 \mathrm{rpm}$. Upon completion of melt blending, the extruded strands were allowed to cool in the water bath, and then cut into pellets using a pelletizer. The two sets of PBT composites which were produced in the present investigation and their corresponding compositions are shown in table 1 .

Finally, the tensile and impact test specimens were prepared, by using Ferromatic Milacron (Model-Omega $80 \mathrm{~W}$ ) injection-molding machine from the pellets, which were again dried in an oven at $110^{\circ} \mathrm{C}$ for $3 \mathrm{~h}$ prior to molding. The geometry of the tensile and impact test specimens was according to ASTM D 638 and ASTM D256 specifications, respectively.

\subsection{Mechanical testing}

The tensile strength and elongation at break were measured with a universal testing machine (LLOYD-EZ-20) at a crosshead speed of $50 \mathrm{~mm} / \mathrm{min}$. Five specimens were sampled from each composite for measurement. The five test results were averaged and then reported.

Table 1. Compositions of $\mathrm{PBT} / \mathrm{CaCO}_{3}$ composites.

\begin{tabular}{|c|c|c|c|}
\hline \multicolumn{2}{|c|}{$\begin{array}{l}\mathrm{C} \text { set compositions } \\
\mathrm{PBT} / \mathrm{uncoated} \mathrm{CaCO}_{3}(\mathrm{w} / \mathrm{w})\end{array}$} & \multicolumn{2}{|c|}{$\begin{array}{c}\text { S set compositions } \\
\text { PBT/SA coated } \mathrm{CaCO}_{3}(\mathrm{w} / \mathrm{w})\end{array}$} \\
\hline $\mathrm{C} 1$ & $95 / 5$ & S1 & $95 / 5$ \\
\hline C2 & $90 / 10$ & S2 & $90 / 10$ \\
\hline C3 & $80 / 20$ & S3 & $80 / 20$ \\
\hline $\mathrm{C} 4$ & $70 / 30$ & S4 & $70 / 30$ \\
\hline
\end{tabular}

The Izod notched impact resistance of the composite system was measured using Izod Impact Testing Machine (International Engineering Industries).

\subsection{DSC analysis}

A differential scanning calorimeter (model DSC821, Mettler Toledo) was used to examine the thermal properties of the PBT/ $/ \mathrm{CaCO}_{3}$ composites. About $10 \mathrm{mg}$ of samples were two-stage-heated as follows: first, the sample was heated from $30-250^{\circ} \mathrm{C}$ at a heating rate of $10^{\circ} \mathrm{C} / \mathrm{min}$ and then held there for $5 \mathrm{~min}$. Subsequently the sample was cooled to room temperature at a cooling rate of $10^{\circ} \mathrm{C} / \mathrm{min}$. Then in order to observe melting after crystallization it was reheated from $30-250^{\circ} \mathrm{C}$ at a heating rate of $10^{\circ} \mathrm{C} / \mathrm{min}$.

\subsection{Thermogravimetric analysis}

The thermal stability of the samples was measured by means of thermogravimetric analysis (TG) with a Perkin Elmer Diamond TG/DTA. Each sample was heated from $30-500^{\circ} \mathrm{C}$ at a scanning rate of $10^{\circ} \mathrm{C} / \mathrm{min}$ under Argon atmosphere. The thermal parameters like thermal degradation, onset temperature, the temperature at the maximum rate of weight loss $\left(T_{\max }\right)$, and the \% weight loss of $\mathrm{PBT} / \mathrm{CaCO}_{3}$ were calculated from the obtained TGA and DTA thermograms.

\subsection{X-ray diffraction}

XRD pattern of as molded PBT composite was recorded on Philips X'Pert Pro PANalytical PW 3040/60 diffractometer. Ni filtered $\mathrm{CuK} \alpha$ radiation $(\lambda=1.54 \AA)$ generated at $45 \mathrm{kV}$ and $40 \mathrm{~mA}$ was used for the angle $(2 \theta)$ range from $10-80^{\circ}$. The scan step size and time per step was $0.01^{\circ}$ and $15 \mathrm{~s}$, respectively.

\subsection{Scanning electron microscopy}

Scanning electron microscopic (SEM) pictures were taken to study the morphology of the composites. Samples were immersed into liquid nitrogen and then fractured. The morphology of fractured surfaces was then studied with JEOL 6380A scanning electron microscope after the samples were sputter-coated with a thin platinum layer.

\subsection{FT-IR spectroscopy}

Infrared spectra of $\mathrm{PBT} / \mathrm{CaCO}_{3}$ composite were recorded using a Perkin Elmer Spectrum One FTIR. As the state of samples was thin film ( $5 \mathrm{~mm}$ thickness), the attenuated total reflectance (ATR) technique using zinc selenide $(\mathrm{ZnSe})$ crystal having incident angle at $45^{\circ}$ and scan number, 20 was used. 


\section{Results and discussion}

\subsection{Mechanical properties}

Table 2 presents the results of tensile and impact tests for both the composite systems. As can be seen, composite system containing uncoated $\mathrm{CaCO}_{3}$ shows lower tensile strength values as compared to the composite system containing $\mathrm{SA}$ coated $\mathrm{CaCO}_{3}$ and neat PBT. Also, here the \% elongation value decreases with the increasing content of $\mathrm{CaCO}_{3}$. In case of composite systems containing SA coated $\mathrm{CaCO}_{3}$ the tensile strength and \% elongation initially decreases and then increases. In the S3 composite (20 weight\%) the tensile strength increased from 56$58.9 \mathrm{MPa}$ which is about $5 \%$ higher than pure PBT and has a \% elongation value better than all other composites.

In case of notched Izod impact strength, the impact value decreases by about only $18 \%$ in the composite system containing uncoated $\mathrm{CaCO}_{3}$ and also this decrease is constant for all the weight $\%$ of $\mathrm{CaCO}_{3}$ added. Whereas in case of composite system containing SA coated $\mathrm{CaCO}_{3}$, again the $\mathrm{S} 3$ system shows impact strength value better than all other composites and similar to that of pure PBT.

The better mechanical properties of S3 system among all the composites can be attributed to the fact that the stearic acid coating imparts hydrophobic characteristics on $\mathrm{CaCO}_{3}$ surface, thereby promoting adhesion between the particles and PBT matrix and thus improving the dispersion and compatibility between the phases.

\subsection{Differential scanning calorimetry (DSC)}

DSC measurements were carried out to determine the thermal properties such as melting temperature $\left(T_{\mathrm{m}}\right)$, heat of crystallization $\left(H_{\mathrm{c}}\right)$, degree of crystallinity, onset crystallization temperature $\left(T_{\mathrm{on}}\right)$, and peak crystallization temperature $\left(T_{\mathrm{c}}\right)$ of PBT composites. The DSC heating, cooling and heating curves are shown in figure 1. From the recorded heating and cooling curves, thermal properties were calculated which are tabulated in table 3 . The

Table 2. Mechanical properties of PBT/uncoated $\mathrm{CaCO}_{3}$ and PBT/SA coated $\mathrm{CaCO}_{3}$ composites.

\begin{tabular}{lccc}
\hline Sample & $\begin{array}{c}\text { Tensile at yield } \\
(\mathrm{MPa})\end{array}$ & $\begin{array}{c}\text { \% Elongation } \\
\text { at break }\end{array}$ & $\begin{array}{c}\text { Izod impact } \\
\text { strength }(\mathrm{J} / \mathrm{m})\end{array}$ \\
\hline PBT & 56.408 & 27.4 & 39 \\
C1 & 51.166 & 7.85 & 32 \\
C2 & 51.362 & 6.56 & 32 \\
C3 & 53.299 & 6.45 & 32 \\
C4 & 50.406 & 5.54 & 32 \\
S1 & 52.711 & 4.97 & 32 \\
S2 & 53.397 & 6.15 & 32 \\
S3 & 58.938 & 8.53 & 39 \\
S4 & 50.235 & 5.03 & 29 \\
\hline
\end{tabular}

crystallinity percentage of PBT constituent in composite was determined by (Liu et al 1997)

$$
\chi_{\mathrm{c}}(\% \text { Crystallinity })=\Delta H_{\mathrm{m}} / \Delta H_{\mathrm{m}}^{\circ} w \times 100,
$$

where $\Delta H_{\mathrm{m}}^{\circ}$ is the heat of fusion $(140 \mathrm{~J} / \mathrm{g}$ ) for $100 \%$ crystalline PBT (Brozaa 2005) and $w$ the mass fraction of PBT in the composites.

From figures $1 \mathrm{a}$ and $\mathrm{d}$ it is observed that melting point of first heating is not affected by the presence of $\mathrm{CaCO}_{3}$ in both the composite systems. However, $\mathrm{CaCO}_{3}$ did accelerate crystallization during cooling which is evident from the higher crystallization peak temperatures in both the composite systems (about $6^{\circ} \mathrm{C}$ higher when compared to neat PBT) (figures $1 \mathrm{~b}$ and e) which increased with the increasing content of $\mathrm{CaCO}_{3}$.

Also the \% crystallinity of both the composite systems was found to be greater than virgin PBT, which indicates that $\mathrm{CaCO}_{3}$ acts as a nucleating agent during the crystallization of composites. But between the two composite systems, the crystallinity of PBT composites containing uncoated $\mathrm{CaCO}_{3}$ was found to be higher than that of the other system containing SA coated $\mathrm{CaCO}_{3}$. This is because, the treatment of $\mathrm{CaCO}_{3}$ with stearic acid, apparently reduces the surface energy of the $\mathrm{CaCO}_{3}$ particles and therefore, it cannot act as strong nucleating species as has been reported earlier (Papirer et al 1984).

However, the 2nd heating shows some differences (figures 1c and $\mathrm{f}$ ). The composites and neat PBT show double melting peaks, which is interpreted in terms of reorganization processes occurring during the 2 nd heating and has been reported earlier also (Xiao and $\mathrm{Hu} 2005$ ). The results confirm that the addition of a $\mathrm{CaCO}_{3}$ enhances the nucleation process on PBT crystallization.

\subsection{Thermogravimetric analysis}

TGA was used to study the thermal stability of PBT composites and the results are listed in table 4 . Figure 2 shows the \% weight loss vs temperature curves for PBT and $\mathrm{SA}$ coated $\mathrm{CaCO}_{3}$. From the thermogram, it is observed that PBT undergoes degradation at about $375^{\circ} \mathrm{C}$, whereas in $\mathrm{CaCO}_{3}$ light weight loss is observed between 350 and $400^{\circ} \mathrm{C}$ which is associated with the degradation of stearic acid, after which it is stable up to $600^{\circ} \mathrm{C}$ and finally degrades to $\mathrm{CaO}$ at $600^{\circ} \mathrm{C}$. Figure 3 shows the TGA and DTA thermograms of two sets of $\mathrm{PBT} / \mathrm{CaCO}_{3}$ composites and PBT polymer.

As can be seen, the incorporation of the uncoated and coated $\mathrm{CaCO}_{3}$ into the PBT matrix has enhanced the thermal stability of both the composites, which is evident from the increased onset of thermal degradation temperature. Also in both the composite systems, the $T_{\max }$ increased with the increasing content of $\mathrm{CaCO}_{3}$. This can be interpreted in terms that the initial degradation products of PBT, which accelerate further degradation process, are 

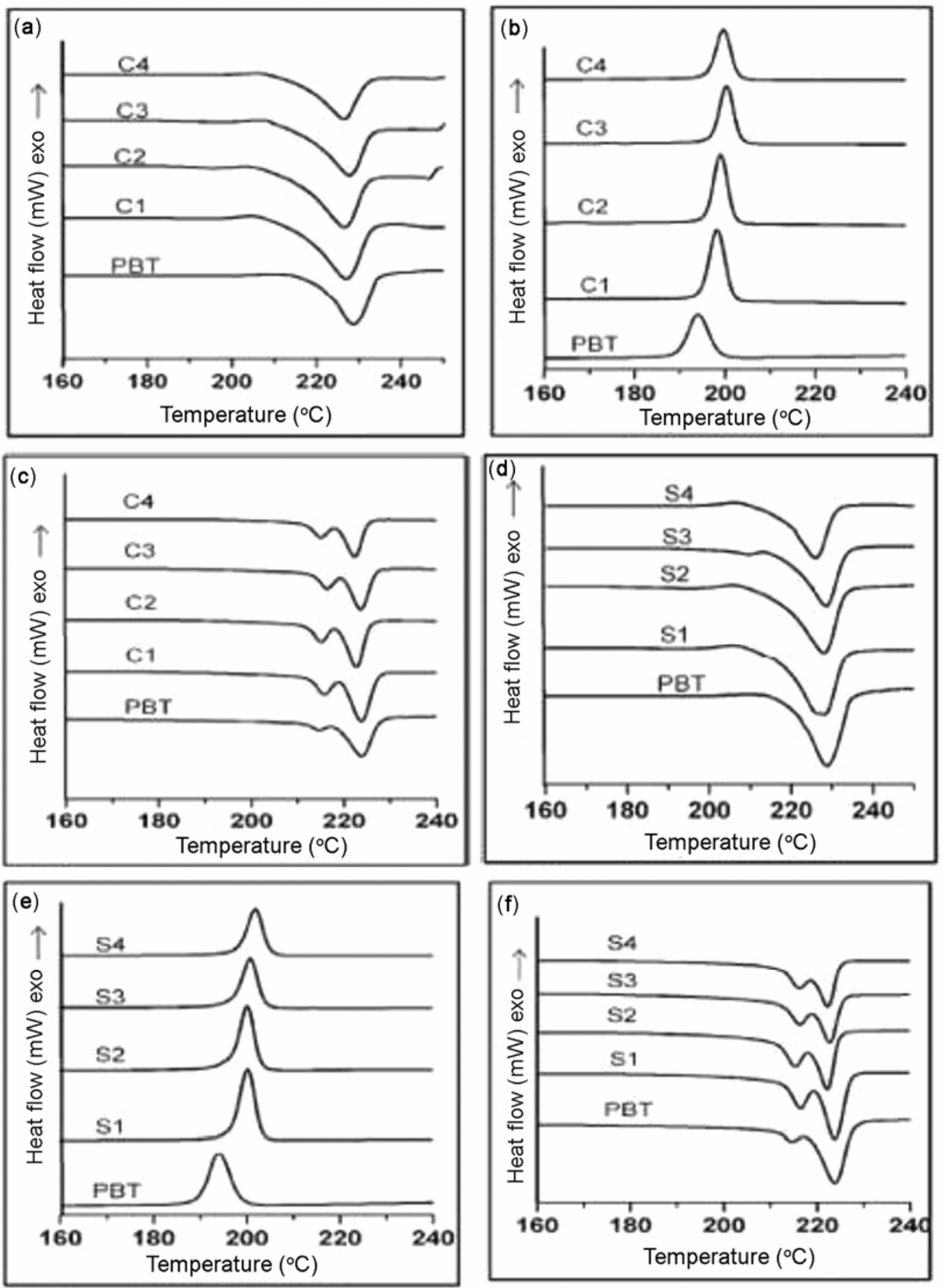

Figure 1. DSC curves of 1 st heating, cooling and 2 nd heating of $\mathrm{PBT} / \mathrm{CaCO}_{3}$ composites. (a) 1 st heating, (b) cooling, (c) 2nd heating of C composite system; (d) 1st heating, (e) cooling and (f) 2nd heating of S composite system.

absorbed by the $\mathrm{CaCO}_{3}$ surface thus increasing the temperature of the point of maximum degradation $\left(T_{\max }\right)$.

\subsection{X-ray diffraction}

Figure 4 shows X-ray diffractogram for pure PBT and $\mathrm{CaCO}_{3}$. In virgin $\mathrm{PBT}$ the diffraction peaks are observed at $2 \theta$ Braggs angle of $15 \cdot 5^{\circ}, 16 \cdot 8^{\circ}, 20 \cdot 2^{\circ}, 22 \cdot 9^{\circ}$ and $24 \cdot 2^{\circ}$, corresponding to diffraction planes $\left(\begin{array}{lll}0 & 1 & 1\end{array}\right),\left(\begin{array}{lll}0 & 1 & 0\end{array}\right)$, (1 $\left.\begin{array}{lll}0 & 1\end{array}\right),\left(\begin{array}{lll}1 & 0 & 0\end{array}\right),\left(\begin{array}{lll}1 & 1 & 1\end{array}\right)$ which are characteristic of the $\alpha$ form (Hall and Pass 1976; Desborough and Hall 1977) of PBT with triclinic crystal structure, whereas $\mathrm{CaCO}_{3}$ shows the calcite crystal structure which is confirmed by the $100 \%$ intensity peak appearing at about $29 \cdot 4^{\circ}$. 
Table 3. Thermal parameters of $\mathrm{PBT} / \mathrm{CaCO}_{3}$ composites.

\begin{tabular}{|c|c|c|c|c|c|c|c|c|}
\hline \multirow[b]{2}{*}{ Sample } & \multicolumn{3}{|c|}{ First heat } & \multicolumn{3}{|c|}{ Cooling } & \multicolumn{2}{|c|}{ Second heat } \\
\hline & $T_{\mathrm{m}}\left({ }^{\circ} \mathrm{C}\right)$ & $\Delta H_{\mathrm{m}}(\mathrm{J} / \mathrm{g})$ & $X_{\mathrm{c}}(\%)$ & $T_{\mathrm{c}}$ onset $\left({ }^{\circ} \mathrm{C}\right)$ & $T_{\text {c peak }}\left({ }^{\circ} \mathrm{C}\right)$ & $\Delta H_{\mathrm{c}}(\mathrm{J} / \mathrm{g})$ & $T_{\mathrm{ml}}\left({ }^{\circ} \mathrm{C}\right)$ & $T_{m 2}\left({ }^{\circ} \mathrm{C}\right)$ \\
\hline PBT & $228 \cdot 5$ & $48 \cdot 1$ & $34 \cdot 3$ & $198 \cdot 3$ & 194.4 & $46 \cdot 99$ & 214.4 & $224 \cdot 1$ \\
\hline $\mathrm{C} 1$ & $226 \cdot 3$ & 52.5 & 39.4 & 201.7 & $199 \cdot 6$ & 49.5 & $215 \cdot 1$ & $223 \cdot 2$ \\
\hline $\mathrm{C} 2$ & $227 \cdot 5$ & $49 \cdot 1$ & 38.9 & $202 \cdot 1$ & $200 \cdot 4$ & $41 \cdot 4$ & $215 \cdot 3$ & $223 \cdot 1$ \\
\hline C3 & 227.4 & $43 \cdot 2$ & 38.5 & $203 \cdot 3$ & 201.4 & 39.88 & $216 \cdot 1$ & $223 \cdot 4$ \\
\hline $\mathrm{C} 4$ & 226 & $37 \cdot 4$ & $38 \cdot 1$ & $202 \cdot 9$ & $200 \cdot 7$ & $35 \cdot 6$ & $215 \cdot 2$ & $222 \cdot 8$ \\
\hline S1 & $227 \cdot 7$ & $49 \cdot 01$ & $36 \cdot 8$ & 202.7 & $200 \cdot 1$ & $42 \cdot 1$ & $215 \cdot 9$ & $223 \cdot 7$ \\
\hline S2 & 227.4 & $46 \cdot 2$ & $36 \cdot 6$ & $203 \cdot 1$ & $201 \cdot 3$ & 38.04 & 215.7 & $223 \cdot 3$ \\
\hline S3 & 227.7 & $40 \cdot 8$ & $36 \cdot 4$ & $204 \cdot 1$ & 201.9 & $32 \cdot 3$ & $216 \cdot 7$ & $223 \cdot 7$ \\
\hline S4 & $226 \cdot 8$ & $35 \cdot 7$ & $36 \cdot 4$ & 204.9 & $202 \cdot 6$ & $29 \cdot 5$ & $216 \cdot 6$ & $223 \cdot 1$ \\
\hline
\end{tabular}

Table 4. Thermal degradation of $\mathrm{PBT} / \mathrm{CaCO}_{3}$ composites.

\begin{tabular}{lrrrrrrrrr}
\hline Sample & PBT & \multicolumn{1}{c}{ C1 } & \multicolumn{1}{c}{ C2 } & \multicolumn{1}{c}{ C3 } & C4 & S1 & S2 & S3 & S4 \\
\hline Onset $T\left({ }^{\circ} \mathrm{C}\right)$ & $377 \cdot 1$ & $382 \cdot 1$ & $384 \cdot 2$ & $384 \cdot 1$ & $381 \cdot 1$ & $379 \cdot 2$ & $381 \cdot 6$ & $380 \cdot 8$ & $379 \cdot 5$ \\
$T_{\text {max }}\left({ }^{\circ} \mathrm{C}\right)$ & $395 \cdot 8$ & $399 \cdot 8$ & $402 \cdot 5$ & $406 \cdot 9$ & $407 \cdot 6$ & $398 \cdot 1$ & $403 \cdot 1$ & $405 \cdot 3$ & $405 \cdot 3$ \\
Residual wt.\% & $2 \cdot 1$ & $6 \cdot 7$ & $11 \cdot 3$ & $24 \cdot 4$ & 34.9 & 4.1 & $17 \cdot 7$ & 24.5 & 35.9 \\
\hline
\end{tabular}

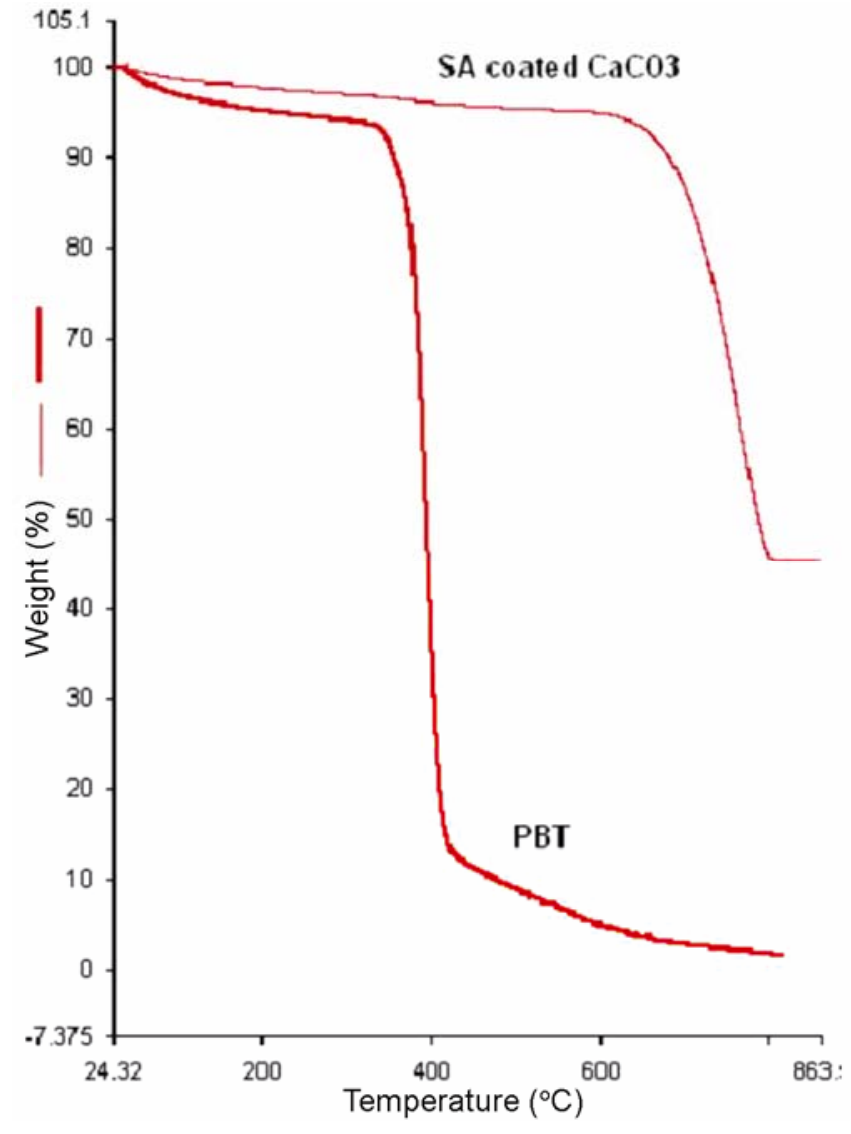

Figure 2. TGA curves of PBT and SA coated $\mathrm{CaCO}_{3}$.

Figures 5a and $\mathrm{b}$ present the X-ray diffractograms of two sets of $\mathrm{PBT} / \mathrm{CaCO}_{3}$ composites. Apparently, apart from those of pure constitutes, no new diffracting peaks were observed in the diffraction pattern of the composites. Moreover, all composite systems showed the same XRD patterns with varying peak intensity in proportion of the constituent's weight fraction. The absence of new diffraction peaks showed that the presence of $\mathrm{CaCO}_{3}$ did not change the crystal structure of PBT.

\subsection{Morphology}

Figure 6 shows the SEM micrographs of uncoated and $\mathrm{SA}$ coated $\mathrm{CaCO}_{3}$. As can be seen in case of uncoated $\mathrm{CaCO}_{3}$, there is strong particle-particle interaction with a tendency to form aggregates whose dimensions are higher than that of isolated particles. In figure 7, the scanning electron micrographs of the composites are exhibited.

In the samples reinforced with uncoated $\mathrm{CaCO}_{3}$ (figures $7 \mathrm{a}$ and $\mathrm{c}$ ) it is observed that $\mathrm{CaCO}_{3}$ particles are poorly welded to the PBT matrix, that is also evident from the SEM micrographs of C3 composite at higher magnification (figure 7e). Here fracture lines and air voids are observed at the borderline of filler, which are formed as a result of detachment of the unembedded particles during fracture in liquid nitrogen, indicating that there is poor adhesion between the filler and the matrix. In samples containing SA coated $\mathrm{CaCO}_{3}$ (figures $7 \mathrm{~b}$ and $\mathrm{d}$ ) the particles are found, better welded to the PBT matrix and also no fracture lines and voids are present at the interface suggesting that the coating of $\mathrm{CaCO}_{3}$ with stearic acid promotes adhesion between the particles and PBT matrix thus improving the compatibility between the phases. 

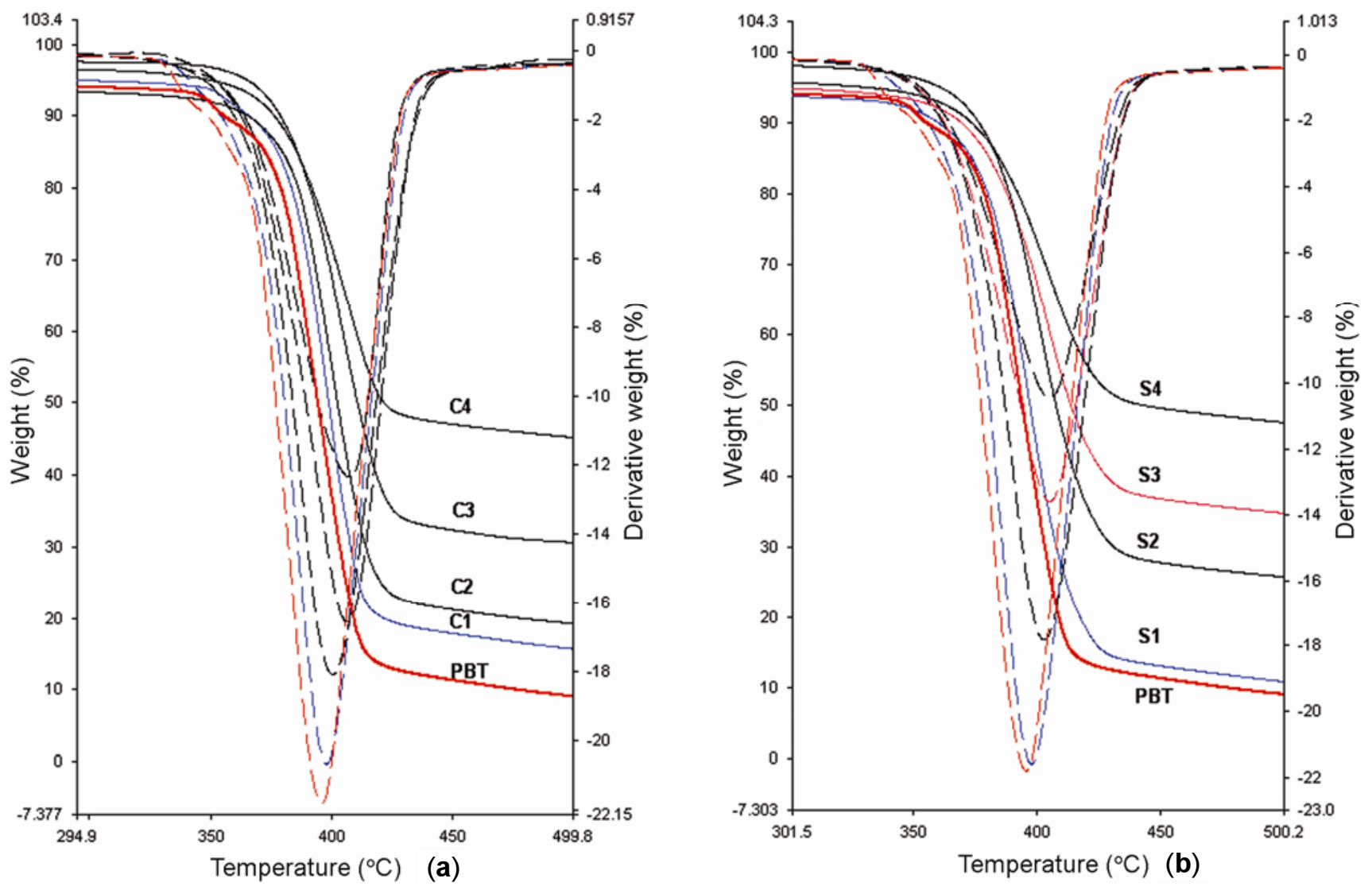

Figure 3. TGA and DTA curves of $\mathrm{PBT} / \mathrm{CaCO}_{3}$ composites: (a) $\mathrm{C}$ composite system and (b) $\mathrm{S}$ composite system.
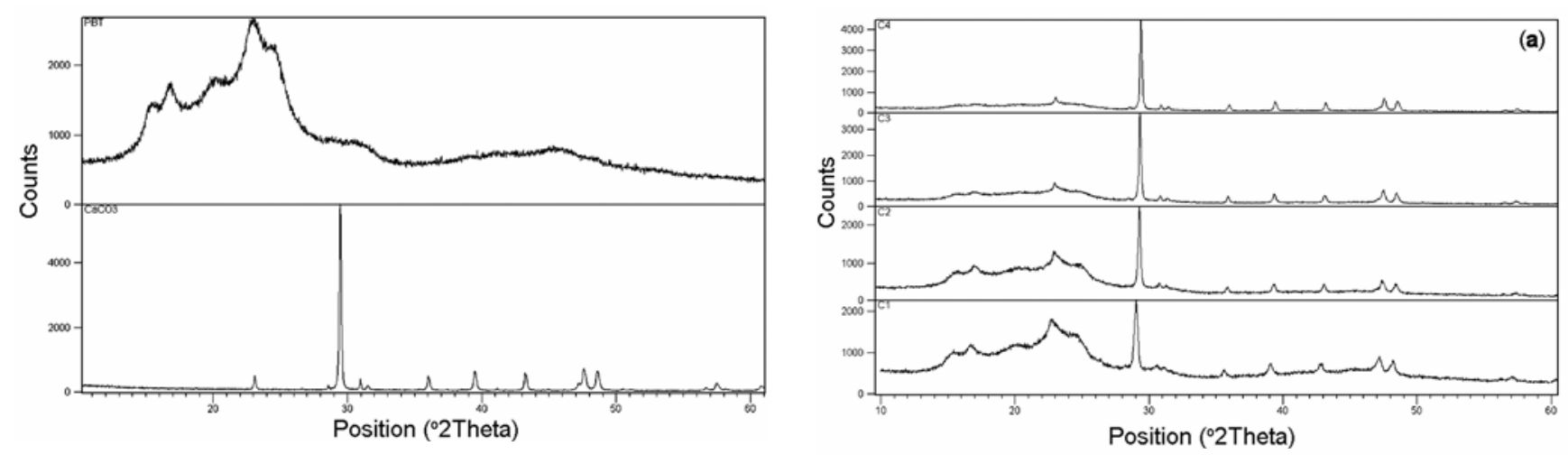

Figure 4. X-ray diffractogram of $\mathrm{PBT}$ and $\mathrm{CaCO}_{3}$.

\subsection{FTIR}

Figure 8 shows FTIR spectra of PBT and $\mathrm{CaCO}_{3}$. The typical IR bands of PBT appear at 2925, $2853\left(\mathrm{CH}_{2}\right.$ stretching), 1707 ( $\mathrm{C}=\mathrm{O}$ stretch), $1456(\mathrm{C}-\mathrm{H}$ bending in $\mathrm{CH}_{2}$ group), 1407 (arom. ring), 1241 (CO-O stretch in esters), $1115\left(\mathrm{O}-\mathrm{CH}_{2}\right), 1018$ (arom. ring) and $723 \mathrm{~cm}^{-1}$ (aromatic $\mathrm{C}-\mathrm{H}$ bending). The calcium carbonate spectrum shows IR bands at $1084,878,1455,713 \mathrm{~cm}^{-1}$ corresponding to $v 1$-symmetric stretching, $v 2$-symmetric

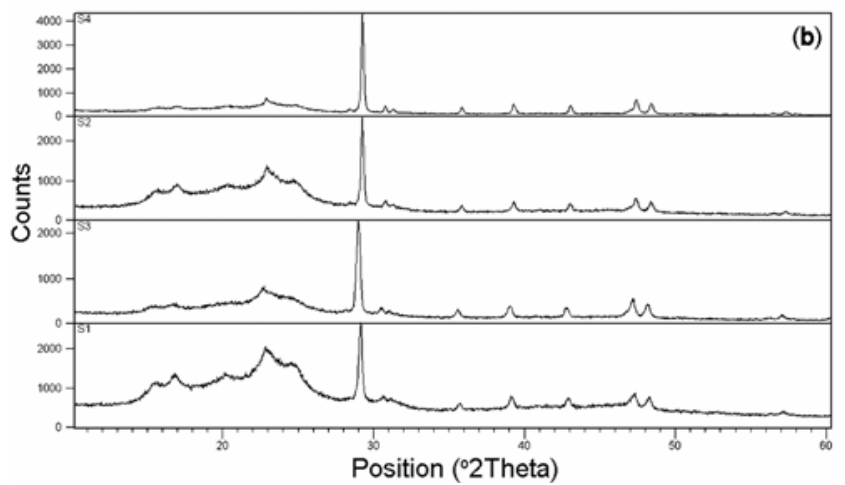

Figure 5. X-ray diffractograms of $\mathrm{PBT} / \mathrm{CaCO}_{3}$ composites: (a) C composite system and (b) $\mathrm{S}$ composite system. 


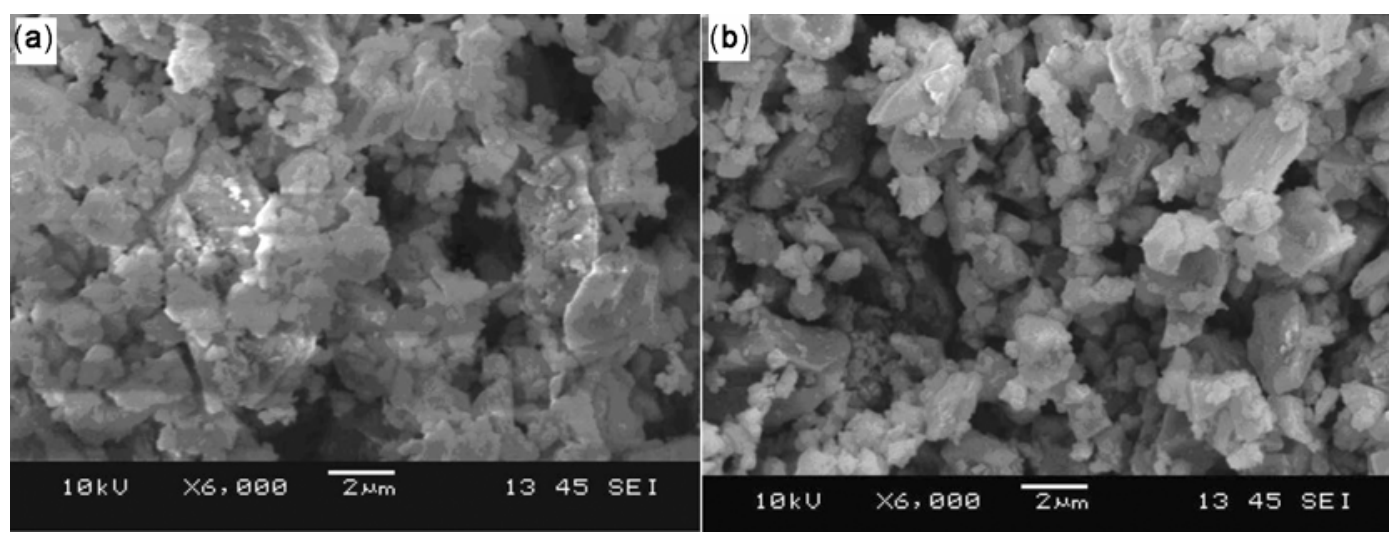

Figure 6. Scanning electron microscopic images of $\mathrm{CaCO}_{3}$ particles: (a) uncoated and (b) SA coated particles.
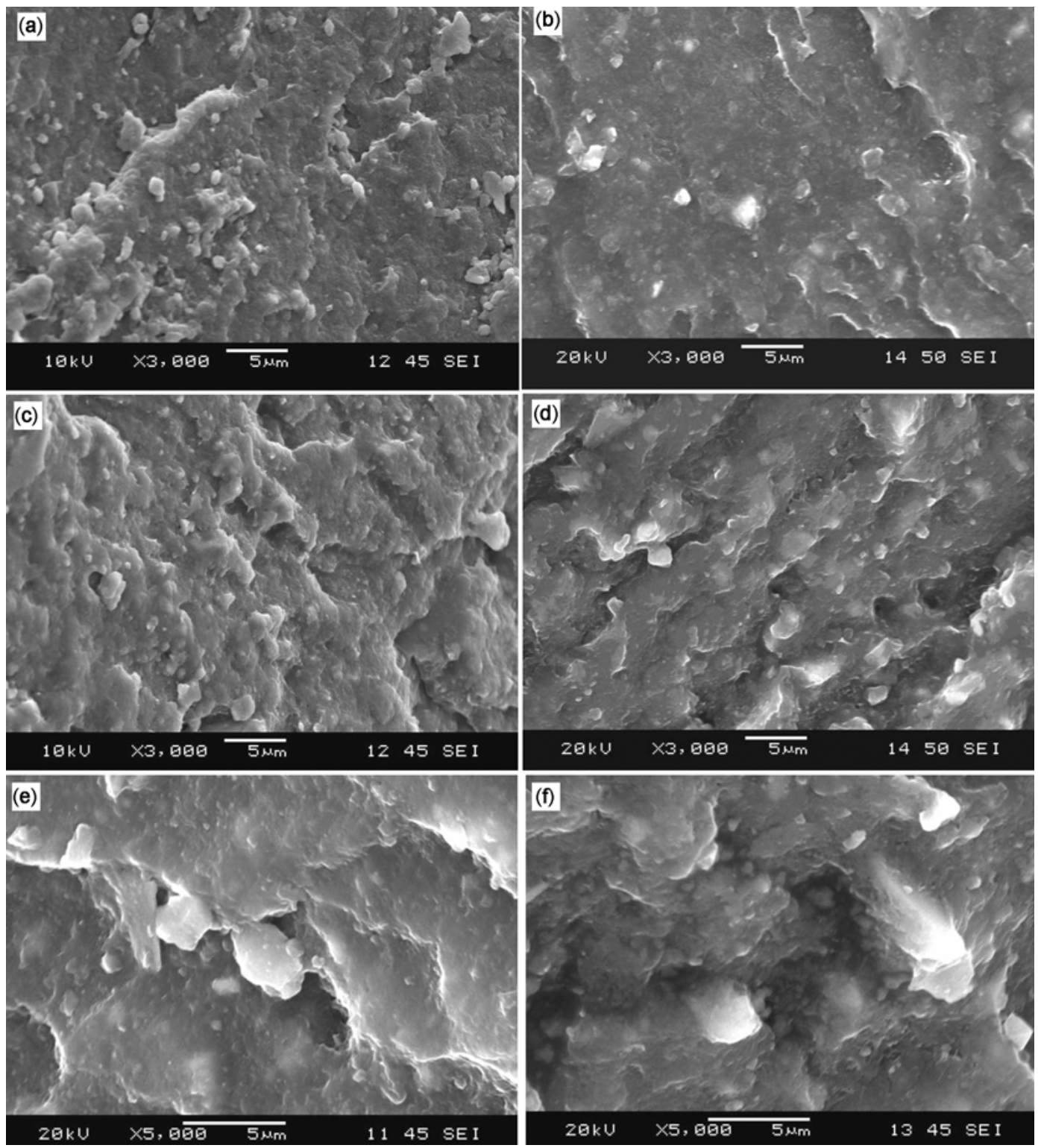

Figure 7. Scanning electron micrographs of the $\mathrm{PBT} / \mathrm{CaCO}_{3}$ composites: (a) and (e) $\mathrm{C} 3$ composite, (b) and (f) S3 composite, (c) C4 composite and (d) S4 composite. 


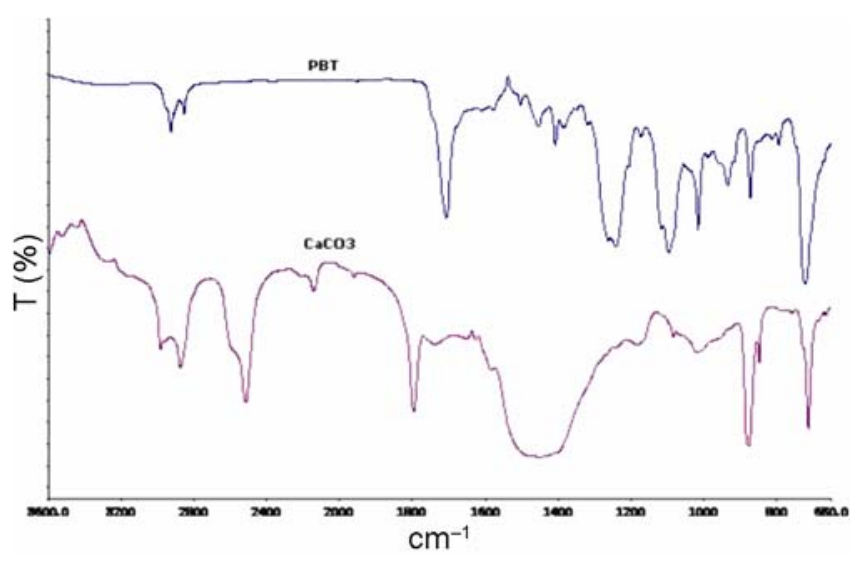

Figure 8. Infrared spectra of $\mathrm{PBT}$ and $\mathrm{CaCO}_{3}$.
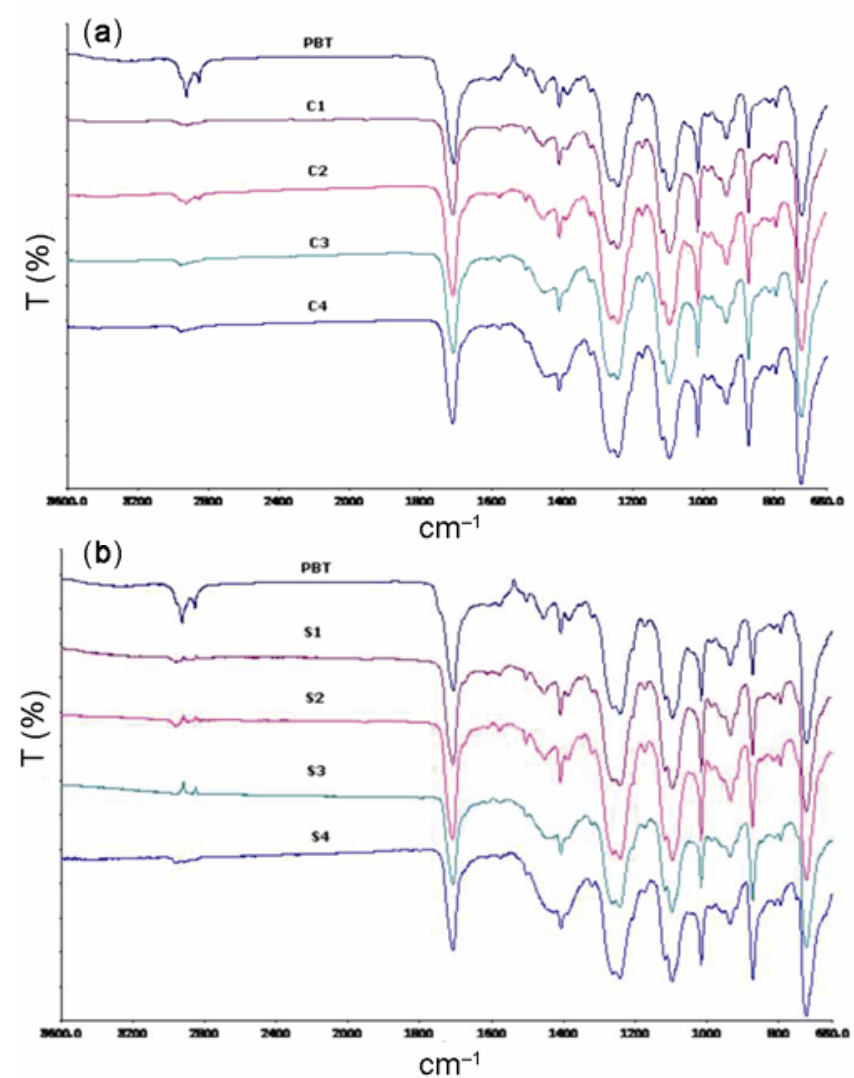

Figure 9. Infrared spectra of $\mathrm{PBT} / \mathrm{CaCO}_{3}$ composites: (a) $\mathrm{C}$ composite system and (b) S composite system.

bending, v3-asymmetric stretching and v4-asymmetric bending vibrations, which are characteristic of the calcite structure (Alder and Kerr 1962).

Figure 9 presents FTIR spectra for $\mathrm{PBT} / \mathrm{CaCO}_{3} \mathrm{com}$ posites. It is observed that in both composite systems with the addition of $\mathrm{CaCO}_{3}$, the IR band at $1455 \mathrm{~cm}^{-1}$ appeared in the spectrum, which is typical of $\mathrm{CaCO}_{3}$ and its absorption increased with the increasing content of $\mathrm{CaCO}_{3}$. But apart from this no new IR band was observed in the composites indicating that no bonding has taken place between $\mathrm{CaCO}_{3}$ and PBT matrix.

Thus from the FTIR analysis it can be concluded that stearic acid coating on $\mathrm{CaCO}_{3}$ helps in improving the compatibility between the filler and matrix but as such does not help in binding the filler with the PBT matrix and this improved compatibility is responsible for the better mechanical properties of composites containing stearic acid coated $\mathrm{CaCO}_{3}$ as compared to composite containing uncoated $\mathrm{CaCO}_{3}$.

\section{Conclusions}

The mechanical, thermal, and structural properties of $\mathrm{PBT} / \mathrm{CaCO}_{3}$ composites were studied by addition of two different types of $\mathrm{CaCO}_{3}$, uncoated and $\mathrm{SA}$ coated $\mathrm{CaCO}_{3}$. The results of different tests clearly demonstrate that PBT composites containing SA coated $\mathrm{CaCO}_{3}$ exhibit better mechanical properties, with the S3 composition showing the best combination of properties where the tensile strength has increased from $56 \mathrm{MPa}$ to 58.9 $\mathrm{MPa}$ and has an impact strength similar to that of neat PBT. A better polymer-filler interaction with increased adhesion between the polymer and filler particles has resulted in enhancing the mechanical properties of the $\mathrm{S}$ system. Also the thermal studies show an increase in \% crystallinity, crystallization temperature and thermal stability in both the composite systems. All of the results indicate that $\mathrm{CaCO}_{3}$ is a good candidate for use as a reinforcing agent in PBT for future applications in electronics and automobile sector.

\section{Acknowledgements}

The author is thankful to the Visvesvaraya National Institute of Technology, Nagpur, for providing a research fellowship to work on this area of polymer composites.

\section{References}

Alder Hans H and Kerr Paul F 1962 The American Mineralogist 471962

Brozaa G and Kwiatkowskab M 2005 Polymer 465860

Desborough J and Hall I H 1977 Polymer 18825

Hall H and Pass M G 1976 Polymer 17807

Liu Z, Maréchal P and Jérôme R 1997 Polymer 384925

Papirer E, Schultz J and Turchi C 1984 Eur. Polym. J. 201155

Xiao Junfeng and Hu Yuan 2005 Eur. Polym. J. 411030 